\title{
Interest-based engineering challenges phase I: Understanding students' per- sonal, classroom, engineering, and career interests
}

\section{Cole H Joslyn, Purdue University, West Lafayette}

Cole Joslyn is a PhD student in the School of Engineering Education at Purdue University. His research interests include holistic approaches to humanizing engineering education (such as ethics of care, humanistic education, contemplative and reflective practices, and spirituality) and how it can shape engineering as a socially just profession in service to humanity. He holds a B.S. in Industrial Engineering and a M.Ed. specializing in mathematics education and has worked as an engineer, a pastor, and a high school math teacher.

\section{Mr. James Holly Jr., INSPIRE Institute, Purdue University}

James Holly Jr. is a Ph.D. Student in Engineering Education at Purdue University. He received a B.S. from Tuskegee University and a M.S. from Michigan State University, both in Mechanical Engineering. His research interest is exploring formal and informal K-12 engineering education learning contexts. Specifically, he is interested in how the engineering design process can be used to emphasize the humanistic side of engineering and investigating how engineering habits of mind can enhance pre-college students' learning abilities.

\section{Dr. Morgan M Hynes, Purdue University, West Lafayette}

Dr. Morgan Hynes is an Assistant Professor in the School of Engineering Education at Purdue University and Director of the FACE Lab research group at Purdue. In his research, Hynes explores the use of engineering to integrate academic subjects in K-12 classrooms. Specific research interests include design metacognition among learners of all ages; the knowledge base for teaching K-12 STEM through engineering; the relationships among the attitudes, beliefs, motivation, cognitive skills, and engineering skills of K-16 engineering learners; and teaching engineering. 


\section{Interest-based engineering challenges phase I: Understanding students' personal, classroom, engineering, and career interests}

Introduction

Engineering as a K-12 endeavor has formal beginnings as early as 2000 when Massachusetts included engineering in its state curriculum frameworks ${ }^{1}$. The past fifteen years have seen increased attention on engineering in the K-12 classroom and was recently included in the Next Generation Science Standards ${ }^{2}$, a set of national standards for science education that give equal attention to the importance of learning engineering. Marzano, Pickering, and McTighe ${ }^{3}$ describe five dimensions of learning: (1) positive attitudes and perceptions about learning; (2) acquiring and integrating knowledge; (3) extending and refining knowledge; (4) using knowledge meaningfully; and (5) productive habits of mind. Mapping this onto learning engineering in the K-12 classroom we condense these dimensions into three educational aims: improving studentsôattitudes, beliefs, and perceptions of engineering (dimension 1); learning engineering concepts/content (dimensions 2-4); and developing engineering design skills and practices (dimension 5). While there has been a considerable amount of work done in improving studentsôattitudes, beliefs, and perceptions of engineering along with promising results, little difference is being made in new or diverse students choosing engineering pathways.

This paper considers the notion that $\mathrm{K}-12$ students are participating in engineering activities and curriculum that are improving perceptions about engineering by appealing to their situational interests, but not necessarily to their personal interests. Krapp, Hidi, and Renninger ${ }^{4}$ describe situational interests as the ônterestingnessôof the social or nonsocial environment that evoke or encourage interactions while personal interests refer to the characteristics of a person that influence his or her engagement and interaction with the social or nonsocial environment. That is to say, hands-on, engineering activities are likely creating environmental contexts that are interesting and engage studentsôinterests; however, these activities may not be appealing to the studentsôpersonal interests that call them to participate regardless of the environmental contexts. This is an important distinction as we hypothesize that persistence (in engineering) results from an individualôs personal desire (or interest) to engage in the activity or discipline.

Therefore, the questions guiding this study are 1) how do studentsôinterests (situational and personal) relate to engineering? and 2) how can studentsôinterests be used to inform development of engineering activities and curricula? In order to investigate how studentsô interests relate to engineering, we conducted an interview study to better understand students (grades 6 - 9) personal interests ranging from personal to academic to career. We expect these findings to help inform the future development of engineering activities and curriculum on being thoughtful in having contexts that appeal to both studentsôsituational and personal interests.

\section{Framework}

The engineering education community (i.e. researchers, practitioners, administrators) is hard at work designing and establishing the presence of engineering education in the K-12 setting, and ensuring its prosperity. Focused efforts give attention to the appropriate engineering content, authentic instructional activities, and sufficient assessment instruments. Nevertheless, these essential aspects of pre-college engineering education only scratch the surface of what is 
necessary to produce the quantity and quality of engineers, and citizens, for which we aspire to as a nation. Because of the ability of engineering to develop technical literacy and critical thinking skills, amongst other attributes, engineering education in the K-12 setting has a greater potential to enrich our citizenry than just expanding the pipeline to the engineering career pathway $^{5,6}$. Therefore, we agree with Cunningham \& Lachapelle ${ }^{7}$ in the following statement:

As we introduce engineering into K-12 education, we must work vigilantly from its inception to ensure that it is inviting and engaging for all students, particularly those who are underserved, underperforming, or underrepresented in STEM fields, including girls, minorities, students from low socio-economic backgrounds, students with individualized education plans, and English-language learners. (p. 117)

With these considerations in mind, we present our research as one component of a larger mission that seeks to provide a framework for K-12 students to engage the engineering design process through their self-determined interests. While organizations such as the National Research Council and National Academy of Engineering communicate concerns for the increase of women and minority participation in engineering, students also need the liberty to express their individual diversity within engineering ${ }^{8}$. Regardless of shared ethnicity, socio-economic status, etc. students are individuals whose interests may differ. Educational experiences, within engineering and in general, should allow students to maintain their individuality while participating in the discipline being learned. Fila et al. ${ }^{9}$ explain, ñn classroom settings, it is important to help students integrate who they are as people and how that identity drives their engagement in engineering practices (e.g. teamwork, design thinking, creativity, problem solving, and communication)ò(p. 729).

Engineering education in pre-college settings provides an opportunity to promote the humanistic side of engineering ${ }^{10}$ and promote more than the technical skills normally emphasized. A number of documents such as The Engineer of 2020: Visions of Engineering in the New Century ${ }^{11}$ are now calling for tomorrow $\hat{Q}$ engineer to have content knowledge and be skilled in areas beyond those traditionally associated with the engineering profession. Furthermore, organizations within the engineering workforce desire a more expansive education

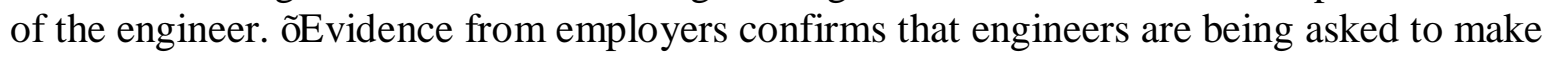
decisions that require, in addition to technical expertise, a keen understanding of broad, sociohumanistic contexts and considerationso $\mathrm{o}^{12}$. Thus, K-12 educators can use the implementation of engineering instruction to develop what are normally deemed ñsoftò skills in their students.

Ethics, teamwork, and communication are essential for a sufficient K-12 engineering education ${ }^{5}$.

For students to develop enthusiasm toward becoming engineers, they must first understand what engineers do. ñThe role of engineers could be better understood if public media represented the profession more prominently and accuratelyơ ${ }^{6}$. Accordingly, engaging students in activities that require them to authentically perform the engineering design process playing the role of engineering for people, and believe it is necessary to learn about our end-user.

For this paper, the student data was collected from six attendees of a summer engineering-focused camp hosted at a large Midwestern University. Following the transcription of the interviews, 
Methods

Interviews were conducted with middle school and high school students that participated in a summer engineering program at a large Midwestern university targeting underrepresented minorities. Students agreed to participate in interviews conducted after the weeklong summer engineering program completed. The students participated in semi-structured interviews over the phone that were recorded and then transcribed for analysis. Each participant was asked three sets of questions. The first set of questions was asked to establish an understanding of each participantô personal interestsð what they typically do on their own time, favorite activities, things they learn about. The second set of questions were asked to learn about their favorite and least favorite subjects in school and to determine if there was a connection or relationship between their interests and favorite/least favorite courses in school. The final set of questions were asked to determine the participantsôunderstanding of engineering work and engineering as a profession as well as their interest in engineering as a career and their ability to align their interests to engineering work.

Participants

A total of six middle school and high school students voluntarily participated in this study. All of the participants attended a summer engineering program at a large Midwestern university targeting underrepresented minorities. The group of participants consisted of four male African-Americans, one female African-American and one male Hispanic. Although this is a small sample size, this study is part of a broader study that investigates how studentsôinterests (situational and personal) relate to engineering.

Analysis

Analysis was conducted by grouping responses according to which set of questions produced the response. Deeper analysis of this diversity in interests was conducted by looking for ways in which participant responses revealed connections to other responses from other question sets, particularly the personal interests set of questions and the engineering set of questions.

Findings

During analysis two main themes emerged. The first theme emerged as we explored the diversity of interests among students. The diversity of interests vary greatly between the participants falling into categories such as music (playing instruments, making songs), literature $\&$ poetry (reading novels, writing stories or poems), outdoor activities (running, walking, playing), and video games (playing). This finding strengthens the idea of individual diversity and highlights the fact that diversity is broader than ethnic considerations ${ }^{13}$. Moreover, educators may examine this information when determining engineering design challenges they believe are relevant to their student population. 
During the interviews students were asked about their favorite activities to partake in, as well as, their career goals and what they planned to do once schooling is completed. Below is an excerpt as one student addresses those questions.

Interviewer(I): What uh what are some of your favorite things to do?

Participant(P): Uh I like to write

I: Ok

P: And I like to play basketball but mostly writing

I: Writing, really Um what uh what do you like about writing?

P: Uh I like making stories and uh making stories and I also like to write music so and that

I: Ok so writing music youô̂e ï are you writing the lyrics to music or are you writing the notes or chord progressions oré

P: I write lyrics

I: Oh ok ok and are those lyrics to melodies that you create on the bass or cello or is it just

P: Sometimes the bass but then I also use this thing that I use for instrumentals and uh yeah I use the piano

I: Oh ok so you play the piano as well?

P: Uh I play I play by ear

I: Ok ok and um so how did you learn um to play these instruments

P: When I was 4 I started to play the cello

I: What do you think you want to do for a job when you decide youôe completed school?

P: I plan to study uh biomedical engineering

I: $\mathrm{Ok}$

P: So I might be like a biologist or a geneticist

I: Ok ok um and what do you like about that particular job or career?

P: Uh I like whenever I went to the [engineering] program uh we had to fix bones chicken bones

I: Ah ok and uh so what did you end up doing for that activity

P: Uh we used uh we uh we broke chicken bones and uh we had to glue them back together so yeah

I: Ok alright um and how did you learn about that that career about biomedical engineering

P: I never uh noticed it until I went to the program

The student displays a clear affection for music, and even mentions a natural ability for hearing and playing music; yet, he decides on a completely different career after one summer program experience. We view instances such as these as opportunities for K-12 engineering education to serve as a connection point between engineering and studentsôpassions. Only one of the six participants described an engineering career they wanted to pursue that was aligned with their personal interests. We want to be cautious about making inferences about these examples, but mention these instances to highlight the potential of engineering education in the pre-college learning environment.

The second theme that emerged was interpreted to be challenges/opportunities for integrating interests into engineering contexts. These challenges/opportunities include: students 
have a limited perception of engineering and what it means to be an engineer; and although participants had relationships with practicing engineers, they did not utilize those relationships as resources for further exploring/understanding engineering.

The issue of studentsôperception of engineering was present in this study, the students communicated a limited viewpoint of what engineers do and what is necessary to be a good engineer. In this excerpt, one student describes what she believes one needs to know or learn to be a good engineer.

I: Ok so um could you see yourself becoming an engineer?

P: Uh yes

I: Yeah um and what do you think you@̂l need to know or learn to be a good engineer?

P: I think you would need to be pretty good in each subject

I: Ok um and which subjects in particular or just?

P: Right oh math, science

I: Ok

P: Physics

The student initially says a person must be proficient in all subjects, which is arguably a good response; but when asked to specify her answer, she relays the traditional subjects associated with engineers. We believe K-12 engineering education has the chance to properly educate pre-college students on what engineers do, as well as, expand studentsôunderstanding of the skills that qualify a good engineer.

Five of the six participants knew practicing engineers (e.g. parent, grandparent, uncle, cousin). However, they could say very little about what the engineer(s) did at work. For example, when we asked one participant if he knew what his Chemical engineer parents did at work he only offered a general response:

I: Oh Iôm sorry Um do you know what your parents do at work as engineers?

$\mathrm{P}: \mathrm{Mm}$ they make plastics

Another participant shared that his uncle is a Civil engineer but he could not tell us what his uncle did at work:

I: Do you know anyone else who is an engineer?

P: My uncle

I: Do you know what he does at work? Like what he does as an engineer?

$\mathrm{P}: \mathrm{He}$ is a civil engineer

I: Do you know what he does? What he does for his job?

P: No. Actually, right now, no.

Discussion

We tried to get insight from students about how their interests align with engineering activities. Based on their responses it seems that the hands on nature of many engineering activities may appeal to studentsôsituational interests but they do not help students connect engineering to their personal interests. We conjecture that engineering programs have an 
excellent opportunity to provide students with a context that would enable students to articulate how their interests align with engineering.

We also noticed that students did not explicitly connect their personal interests to engineering activities. We understand, in hindsight, that this is due to our interview protocol. Trying to be sure that we did not lead students and their responses, we completely left out the question we wanted the participants to answer, ñow do your personal interests relate to engineering?ò

Finally, although we did not explicitly ask participants to identify personal skills/qualities, we began to analyze responses looking for demonstrations of soft skills (such as leadership, initiative, creativity, etc.), self-identified skills they possess, and self-identified skills that they needed. We will explicitly ask such questions in future interviews to explore personal skills that are necessary for engineers.

\section{References}

1. Massachusetts Department of Education. Massachusetts mathematics curriculum framework. (2000). at 〈http://www.doe.mass.edu/frameworks/math/2000/final.pdf>

2. National Research Council. Next generation science standards: For states, by states. (National Academies Press, 2013).

3. Marzano, R. J., Pickering, D. \& McTighe, J. Assessing student outcomes: Performance assessment using the dimensions of learning model. (Association for Supervision and Curriculum Development, 1993).

4. $\quad$ Krapp, A., Hidi, S. \& Renninger, K. A. in Role Interes. Learn. Dev. (Renninger, K. A.) (Lawrence Erlbaum Associates, 1992).

5. Moore, T. J. et al. A Framework for Quality K-12 Engineering Education: Research and Development. $J$. Pre-College Eng. Educ. Res. 4, (2014).

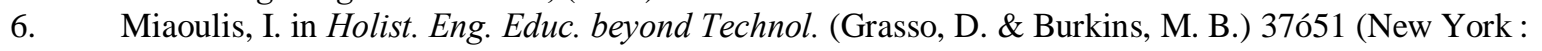
Springer, 2010).

7. Cunningham, C. M. \& Lachapelle, C. P. in Eng. pre-college settings Synth. Res. policy, Pract. (Purzer, S., Strobel, J. \& Cardella, M. E.) 117ï (Purdue University Press, 2014).

8. Foor, C. E., Walden, S. E. \& Trytten, D. A. đ́ wish that I belonged more in this whole engineering group:ô Achieving individual diversity. J. Eng. Educ. 96, $103 \ddot{I} 115$ (2007).

9. Fila, N. D. et al. The people part of engineering: Engineering for, with, and as people. in Proc. - Front. Educ. Conf. FIE 727 ï 735 (2014).

10. Hynes, M. \& Swenson, J. The Humanistic Side of Engineering ElConsidering Social Science and Humanities Dimensions of Engineering in Education and Research. J. Pre-College Eng. Educ. Res. 3, 31 ï 42 (2013).

11. National Academy of Engineering. The engineer of 2020: Visions of engineering in the new century. (National Academies Press, 2004). at <http://books.nap.edu/openbook.php?record_id=10999\&page=1>

12. Fisher, E. \& Mahajan, R. L. Humanistic enhancement of engineering: liberalizing the technical curriculum. in Proc. Int. Conf. Eng. Educ. July 21 25 (2003).

13. Wolf, W. A. Diversity in engineering. Women Eng. ProActive Netw. (2006). 